Bipartisan Policy Center. Access: http://

http://bipartisanpolicy.org.

The website of the Bipartisan Policy Center (BPC), a nonprofit think tank based in Washington, D.C., provides a variety of resources and informed commentary on some of the major public policy issues facing the United States today. The BPC itself was established in 2007 by former Senate Majority Leaders Howard Baker, Tom Daschle, Bob Dole, and George Mitchell, and since then has promoted itself as a politically balanced organization that consciously incorporates the expertise of key figures from both the Democrat and Republican parties in its civic endeavors.

The website itself serves as a hub of the activities and discussions in which the BPC is actively involved. For instance, "Programs" outlines their focused initiatives and task forces, which as of this writing include those related to financial reform, energy innovation, health care, and homeland security, among others. Within "Publications" are a number of fully downloadable documents produced by the BPC, including research reports, white papers, and public testimonials-many of which are direct products of the aforementioned programs. It also contains an annual report that summarizes and analyzes the state of the U.S. government from the past year, as well the BPC's related actions towards it.

Other resources include a listing of national events (such as their noteworthy Bridge-Builder Breakfast series), news and press releases, and various multimedia that further illustrate their specific projects and advocacy efforts. Additional information and opportunities for engagement are also pre-

Joni R. Roberts is associate university librarian for public services and collection development at Willamette University, e-mail: jroberts@willamette.edu, and Carol A. Drost is associate university librarian for technical services at Willamette University, e-mail: cdrost@ willamette.edu sented through its active blog, mailing list, and social media outlets-all of which are visibly featured throughout the site.

In addition to a global search box enabling visitors to search across the entire site, some areas also offer the option to conduct keyword searches within a targeted $\mathrm{BPC}$ project (such as one of the specific task forces listed within "Programs"). Wellorganized and cleanly designed, the site is notable not only for its content, but also in how this content showcases the BPC's mission to support civil dialogue across party lines, and, in doing so, to jointly propose sound solutions to today's pressing challenges. In what can sometimes feel like an increasingly partisan political landscape, the BPC website provides a unique take on the types of products and resolutions that can be created through bipartisan collaboration.-Tarida Anantachai, Syracuse University Libraries, tanantac@syr.edu

Forest History Society. Access: http://www.

foresthistory.org/.

The Forest History Society (FHS) is a nonprofit library and archive located in Durham, North Carolina. According to their homepage, FHS is "dedicated to collecting, preserving, and disseminating forest and conservation history for all to use."

The strength of this website is its "Research Center," which provides access to a variety of databases, including an extensive bibliography of works on environmental history, materials related to the history of the U.S. Forest Service, descriptions and transcripts of oral history interviews with individuals involved in forest management, and guides to environmental history archival collections around the world. It also includes an image collection of more than 30,000 low-resolution images "documenting the history of human interaction with the environment."

From the portal page, users can conduct keyword searches against all the FHS col- 
lections in a single search box, filter results by format, and conduct advanced Boolean searches. The individual databases can also be searched from their own separate interfaces by record fields specific to the format, e.g., images can be searched by photographer or caption, and oral histories can be searched by person interviewed or abstract.

"Digital Collections" features primary source materials on selected topics such as the American Tree Farm System and the work of the 10th and 20th Forestry Engineers in World War I. The "Publications" tab offers books, journals, and films published by the society for purchase, plus an archive of the society's magazine Forest History Today going back to its start in 1995. "Education" features teachers' guides and a downloadable curriculum in environmental history.

The website suffers from some usability problems. It has a confusing interface that uses tabs combined with dropdown menus for navigation, page headings are inconsistent, and there are links that go to the wrong targets. Nevertheless, for its wealth of useful resources that are not available on comparable websites, this site is an excellent starting point for teachers, students and researchers interested in the history of forest management, conservation, and environmental science.-PeterJohnson, Western Carolina University,peterj@wcu.edu

\section{The Gilder Lehrman Institute of American}

History. Access: https://www.gilderlehrman.org.

In 1994, Richard Gilder and Lewis Lehrman founded the Gilder Lehrman Institute of American History. Located in New York City, the institute's goal is to improve and to enhance the quality of history education in secondary schools. The institute offers a wide variety of educational programs for teachers and students across the country, but perhaps the institute's most impressive feature is its website, containing more than 60,000 primary source history documents as its core. To access some of the resources, users need to create an account.
This vast and valuable collection, spanning from the Colonial Era to the present, includes not only familiar documents, such as the Declaration of Independence, but also important and lesser-known documents, such as Abraham Lincoln's 1863 Thanksgiving Proclamation and Civil Rights posters from the 1960s. Each imaged primary source document contains a detailed introduction, as well as material for classroom discussion, making these primary sources useful teaching tools and resources found in one location.

The website, as well as the primary documents themselves, can be easily searched from the site's homepage or from the History by Era link from the homepage, as well. Also convenient and well organized are the separate web pages for students and educators. Students have access to all the site's primary sources, as well as AP U.S. History Examination preparation links, online exhibitions, and numerous multimedia links.

Educators can attend online webinars and enroll in online courses (teachers can enroll in an M.A. degree program in American History). "History Now" provides access to changing and unique online exhibitions, such as "American Poets and American History." "Multimedia" provides a large number of audio and video topics dealing with all aspects of American history narrated and presented by historians and by teachers on a great variety of American history topics. Finally, website visitors can use the "Community" link to save their primary documents of interest and connect, via social media, to others interested in their areas of American history.

Easily navigable and containing a considerable and wide number of American history primary sources, as well as multimedia and continuing education material and webinars, this website provides students and educators with valuable online tools and resources to learn about all aspects of American history. Highly recommended._Larry Cooperman, University of Central Florida Libraries, Lawrence.Cooperman@ucf.edu $\boldsymbol{n}$ 